\title{
O projeto de educação para a Educação Física escolar: um olhar para as políticas educacionais dos últimos vinte anos
}

\section{RESUMO}

Este estudo investigou o projeto de educação para a Educação Física escolar presente nas políticas educacionais do Brasil, nos últimos vinte anos. A dialética materialista foi utilizada como método de análise e a pesquisa bibliográfica e a análise documental, como técnicas de pesquisa. Constatamos com este estudo que o projeto de educação presente na legislação, remete-nos a um projeto neoliberal, que através das políticas educacionais aponta para a privatização da educação. Apesar de alguns documentos oficiais assinalarem a educação física como componente curricular de grande importância para a formação dos alunos, as políticas educacionais implementadas não garantem esta prerrogativa. A legislação vem fragilizando a permanência da educação física escolar no currículo da educação básica, com a reforma do ensino médio e a elaboração da BNCC.

PALAVRAS-CHAVE: Políticas educacionais;

Educação física escolar; Educação básica

\section{Adelina Lorensi Prietto}

Especialista em Educação Física Escolar

Universidade Federal de Santa Maria -

UFSM

Centro de Educação Física e Desportos

Santa Maria, Rio Grande do Sul, Brasil adelinaprietto@hotmail.com

https://orcid.org/0000-0002-6387-0412

\section{Maristela da Silva Souza}

Doutora em Ciência do Movimento Humano

Universidade Federal de Santa Maria -

UFSM

Departamento de Desportos Individuais Santa Maria, Rio Grande do Sul, Brasil maristeladasilvasouza@yahoo.com.br

https://orcid.org/0000-0002-9624-3060 
The education project for school Physical Education: a look at the educational policies of the last twenty years

\begin{abstract}
This study investigated the education project for the Physical Education school present in the educational policies of Brazil in the last twenty years. Materialistic dialectics was used as a method of analysis and bibliographical research and documentary analysis as research techniques. We note with this study that the education project present in the legislation, refers us to a neoliberal project, which through educational policies points to the privatization of education. Although some official documents point to physical education as a major curriculum component for the training of students, the educational policies implemented do not guarantee this prerogative. The legislation has weakened the permanence of school physical education in the curriculum of basic education, with the reform of secondary education and the elaboration of the BNCC.
\end{abstract}

KEYWORDS: Educational policies; Physical education; Basic education

\author{
El proyecto de educación para la Educación Física escolar: una mirada para las políticas \\ educacionales de los últimos veinte años
}

\title{
RESUMEN
}

Este estudio investigó el proyecto de educación para la Educación Física escolar presente en las políticas educativas de Brasil, en los últimos veinte años. La dialéctica materialista fue utilizada como método de análisis y la investigación bibliográfica y el análisis documental, como técnicas de investigación. Constatamos con este estudio que el proyecto de educación presente en la legislación, nos remite a un proyecto neoliberal, que a través de las políticas educativas apunta a la privatización de la educación. A pesar de que algunos documentos oficiales señalan la educación física como componente curricular de gran importancia para la formación de los alumnos, las políticas educativas implementadas no garantizan esta prerrogativa. La legislación viene debilitando la permanencia de la educación física escolar en el currículo de la educación básica, con la reforma de la enseñanza media y la elaboración de la BNCC.

PALABRAS-CLAVE: Políticas educativas; Educación física escolar; Educación básica 


\section{INTRODUÇÃO}

No cenário atual da política educacional brasileira, a educação pública vem passando por um processo de sucessivos desmontes, através de cortes orçamentários e reformas governamentais expressas na legislação, gerando retrocessos que levam a perdas das conquistas relativas ao direito à educação gratuita e de qualidade.

Este estudo apresenta como objetivos analisar as políticas públicas nacionais no que se refere à área da Educação Física Escolar, evidenciando quais as contradições e contribuições para a formação dos alunos, na etapa da educação básica, e o seu possível impacto para a área da educação Física escolar.

Considerando a Escola como uma instituição que está relacionada com a estrutura social mais ampla e reconhecendo a influência que o projeto de educação das vias oficiais exerce no cotidiano escolar, seja na sua implementação ou na construção de subjetividades dos sujeitos ligados diretamente ao contexto escolar, julgamos importante analisar os projetos de educação que foram apresentados nos últimos vinte anos na legislação da educação nacional, de modo particular, a proposta para a Educação Física, compreendendo-a como prática social integrada à sociedade.

Um dos aspectos que direcionam o projeto de educação é a organização do currículo, que vem pautado através das vias oficiais. Neste mesmo período histórico, onde a LDB 9.394/96 foi sancionada, no Plano de Educação do Governo Federal, foram implementados os Parâmetros Curriculares Nacionais - PCNs, com o objetivo de subsidiar a revisão curricular dos estados e municípios, articulando-os com as propostas das escolas, objetivando influenciar a prática pedagógica dos professores

Com a elaboração do Plano Nacional de Educação - PNE 2014 (Lei n ${ }^{\circ}$ 13.005, de 25 de junho de 2014), uma das estratégias apontadas foi a pactuação do Ministério da Educação, em articulação e colaboração com os estados, o Distrito Federal e os municípios, para até 2016, elaborar e encaminhar ao Conselho Nacional de Educação - CNE, precedida de consulta pública nacional, proposta de direitos e objetivos de aprendizagem e desenvolvimento para os alunos, configurando a Base Nacional Comum Curricular - BNCC que servirá de subsídio na construção do currículo das mais de 190 mil escolas de Educação Básica do país, públicas ou particulares.

Outro aspecto polêmico das atuais mudanças na legislação, é a Reforma do Ensino Médio, Lei $N^{\circ} 13.415$, de 16 de fevereiro de 2017, que está em processo de implementação e que altera de maneira profunda o currículo e o projeto de formação humana para os alunos desta etapa da educação básica. 
A partir da LDB 9.394/96 que garantiu a presença da Educação Física no currículo de toda a educação básica, novos referenciais vêm sendo apresentados aos professores como subsídios ao seu trabalho docente.

Entendemos que a relação didática que se expressa na sala de aula, tem sempre no seu bojo uma concepção de ser humano, concepção de educação (física) e concepção de sociedade. Nesse sentido, é necessário verificar qual o posicionamento que essas propostas curriculares têm sobre essas questões.

É importante refletir sobre o alcance que essas leis teriam sobre a construção curricular da Educação Física escolar, qual a influência que poderiam exercer no planejamento das aulas, considerando a autonomia docente, as especificidades das realidades locais, juntamente com as questões da complexidade da vida escolar.

\section{METODOLOGIA}

A proposta deste estudo tem sua referência na base legal e no aprofundamento do projeto de educação apresentado pelas vias oficiais.

A dialética materialista será utilizada como método de análise e a pesquisa bibliográfica e a análise documental, como técnicas de pesquisa.

Os documentos analisados serão a Lei de Diretrizes e Bases da Educação Nacional - LDB 9.394/96; os Parâmetros Curriculares Nacionais- PCNs; a Base Nacional Comum Curricular BNCC, com ênfase no documento da Educação Física, enfocando o trato com o conhecimento nos vários níveis de ensino e a Lei $\mathrm{N}^{\circ} 13.415$ de 16 de fevereiro de 2017- Documento que trata da atual Reforma do Ensino Médio. Para tanto a análise será mediada pelas categorias - Educação Física, Currículo e Legalidade.

Estas categorias, quando entendidas de forma dialética, nos possibilitam compreender a possível interferência das legislações que regem a Educação Física no currículo escolar. Pois como declara Sobral (2012) é possível considerar que o Método Dialético em Marx busca uma racionalidade que opere um desvelamento da realidade,

[...] seu "objeto" de investigação só é "encontrado" por intermédio da mediação histórica, pelos conceitos que o sujeito da pesquisa traz consigo. Portanto, o método científico marxista procura sair do imediatismo para uma compreensão mediada da realidade, buscando uma apreensão do "real" que vai do simples ao complexo, da parte ao todo, singular ao universal, do abstrato ao concreto e da aparência à essência das coisas. (p. 5) 
Concordamos com Gomide (2017) que afirma que as políticas educacionais fazem parte da totalidade social e não podem ser tratadas de modo isolado. Para a autora, a investigação sobre políticas educacionais implica no resgate da historicidade do fenômeno, buscando investigá-lo sob a perspectiva histórica desvelando as contradições, interesses e ideologias que estão por detrás da implementação destas políticas.

\section{O PROJETO DE EDUCAÇÃO NAS PROPOSTAS OFICIAIS}

Um projeto de educação é sustentado através das políticas educacionais que são implementadas por meio da legislação educacional dos planos, projetos e diferentes ações de governo. O discurso do gestor sempre evidencia a busca da qualidade da educação e seus propósitos expressos na Constituição Federal. Para buscar estes objetivos lançam metas que incidem nos aspectos financeiros, administrativos e pedagógicos da gestão educacional. Deste modo, toda política educacional repercute na escola. Para Saviani (2008) política educacional são as decisões que o Estado toma em relação à educação. No Brasil, segundo o autor, ela é caracterizada por uma sucessão de reformas que buscam resolver os problemas da área, mas se apresenta de forma descontínua e pouco efetiva.

Um dos aspectos presente num projeto de educação é a preocupação com o que deve ser ensinado, justificando a inserção de certos conhecimentos no currículo. Estas justificativas são alicerçadas na formação das pessoas e da sociedade que se busca com aquela determinada seleção de conhecimentos, ou seja, um determinado tipo de currículo serve a um determinado tipo de homem e de sociedade. Para isto é necessário conhecer a política do conhecimento oficial que reflete na construção do currículo. Neste sentido questionam-se quais interesses estão por trás deste currículo.

Para Saviani (2003), a Escola tem uma função social. O currículo da escola é o resultado de uma seleção intencional de uma porção da cultura universal produzida historicamente.

Atendendo as determinações da LDB 9.394/96, com a justificativa de revisar os currículos escolares, em 1998 foram elaborados pelo Ministério da Educação os Parâmetros Curriculares Nacionais - PCNs. A partir da proposta neoliberal do Governo Federal vigente naquela época, as escolas foram orientadas a trabalhar nos seus currículos com as novas habilidades e exigências para jovens ingressarem no mercado de trabalho, permeadas pela competição e pela excelência.

No atual contexto histórico da educação brasileira, em conformidade ao que preceituam o Plano Nacional de Educação -PNE e a Conferência Nacional de Educação CONAE, foi elaborada a 
BNCC, cuja finalidade é orientar os sistemas na elaboração de suas propostas curriculares, tendo como fundamento o direito à aprendizagem e ao desenvolvimento.

Entre as posições controversas em relação à BNCC, alguns autores como Pereira e Oliveira (2015) questionam-se sobre as possíveis consequências da implementação da mesma. Os discursos em defesa da BNCC apontam que a mesma pode ser um instrumento de equidade e justiça, dadas às desigualdades regionais, proporcionando oportunidade de integração social às populações que historicamente ficaram fora do processo de escolarização. Os discursos contrários a BNCC alertam que a Base valoriza determinados conhecimentos em prejuízo a toda uma pluralidade existente, pois subtrai determinados saberes e culturas, legitimando e validando a produção hegemônica monocultural. Este fato também pode servir à exclusão, com a possibilidade de reprovação em massa dos que vierem de culturas muito distantes do padrão escolar. Nesse sentido, nega-se a diversidade cultural do nosso País defendida na LDB 9.394/96 e a autonomia docente. Outro aspecto considerado é a questão de o currículo mínimo servir à restrição do que se ensina nos lugares mais desprivilegiados, onde há baixa capacidade técnica dos quadros educacionais.

A partir das atuais mudanças na política educacional, a Medida Provisória 746 foi convertida na Lei $\mathrm{N}^{\circ} 13.415$ de 16 de fevereiro de 2017, conhecida como Reforma do Ensino Médio. Esta alterou a Lei n 9.394 de 20 de dezembro de 1996, que estabelece as Diretrizes e Bases da Educação Nacional, e a Lei n 11.494 de 20 de junho de 2007, que regulamenta o Fundo de Manutenção e Desenvolvimento da Educação Básica e de Valorização dos Profissionais da Educação, a Consolidação das Leis do Trabalho - CLT, aprovada pelo Decreto-Lei $\mathrm{n}^{\circ} 5.452$, de $1^{\circ}$ de maio de 1943, e o Decreto-Lei $n^{\circ} 236$, de 28 de fevereiro de 1967; revoga a Lei $n^{\circ} 11.161$, de 5 de agosto de 2005; e institui a Política de Fomento à Implementação de Escolas do Ensino Médio em Tempo Integral.

A LDB 9.394/96 tem sido retaliada através de Medidas Provisórias, refletindo a quebra de um dos princípios da educação nacional, que consta no artigo 206 da Constituição Federal, inciso sétimo, onde afirma a gestão democrática do ensino público.

Cabe ressaltar, nesse momento, que na área de educação, as ditas "reformas" elaboradas sem diálogo entre os sujeitos que estão envolvidos na ação educativa, professores, gestores e estudantes acabam por não alcançar os seus objetivos.

O Ensino Médio, como etapa final da educação básica, vem constituindo historicamente um desafio para as políticas educacionais. Apesar da democratização do acesso à Escola, os resultados ainda não são os esperados, pois os indicadores de repetência e abandono são elevados, apontando para o fracasso escolar. 
Os índices apresentados no Ideb - Índice de Desenvolvimento da Educação Básica- apontam que $80 \%$ dos jovens de 15 a 17 anos estão no Ensino Médio e 20\% estão fora da escola ou ainda frequentando o ensino fundamental. Porém, apesar deste argumento ser uma das motivações e justificativa para a reforma, esta ainda não consegue responder aos problemas cruciais do ensino médio, que estão relacionados ao trato pedagógico com os conteúdos escolares, valorização do profissional docente e a melhoria da infraestrutura das escolas, temas que estavam sendo discutidos no PNE.

Outra questão a se considerar é a preocupação que uma parcela da juventude tem com a inserção num mundo de trabalho em constantes transformações, gerados pela crise estrutural do capitalismo.

A reforma do ensino médio oferece aos estudantes a opção para seguir um currículo voltado para uma formação profissionalizante e um ensino voltado para a formação geral, dividindo os jovens entre uma carreira técnica e uma trajetória de preparação ao ensino superior.

Há uma tentativa explícita de escantear os componentes curriculares que tratam da estética, da intuição, da liberdade, do movimento, da corporeidade, enfim o que não "serve" de modo imediato para a formação do trabalhador se inserir no mercado de trabalho. Impõe-se, deste modo, uma formação tecnicista em detrimento de uma formação ético-política.

A reforma do ensino médio também está vinculada à BNCC e a sua terceira versão, que trata do Ensino Médio, ainda não foi divulgada. O que se tem definido é que as escolas oferecerão opções de itinerários formativos para os estudantes, sendo que $60 \%$ do tempo será destinado a formação comum definida pela Base e os $40 \%$ de tempo restante será destinado à área de formação escolhida (matemática, linguagens, ciências da natureza, ciências humanas ou formação técnica).

O projeto de educação que essas legislações defendem aponta para uma subordinação da educação aos interesses do mercado. As políticas educacionais, alvos do neoliberalismo, foram marcadas pela redução do financiamento, estímulo à expansão do ensino privado, acirrando a competitividade e a produtividade entre educadores em instituições de ensino. Segundo Lima (2015) a educação passa por um momento de mercantilização. Para a autora o Estado, vem fortalecendo o repasse de verbas públicas para IES privadas como meio de assegurar o acesso ao ensino superior. Estudiosos como Costa e Borghi (2013) relatam a parceria dos municípios com instituições privadas de Educação Infantil como alternativa para atender a demanda de vagas para esta etapa do ensino. 


\section{O PROJETO DE EDUCAÇÃO FÍSICA NOS DOCUMENTOS OFICIAIS APRESENTADOS PELA LEGISLAÇÃO BRASILEIRA}

A LDB 9.394/96 define e regulariza a organização da educação brasileira, conforme os princípios presentes na Constituição Federal. O aspecto legal da disciplina Educação Física, descrita atualmente, no art. 26, $\S 3^{\circ}$ da referida lei, nos diz que a educação física, integrada à proposta pedagógica da escola, é componente curricular obrigatório da educação básica, sendo sua prática facultativa ao aluno: que cumpra jornada de trabalho igual ou superior a seis horas; maior de trinta anos de idade; que estiver prestando serviço militar inicial ou que, em situação similar, estiver obrigado à prática da educação física; amparado pelo Decreto-Lei ${ }^{\circ} 1.044$, de 21 de outubro de 1969; que tenha prole. (BRASIL, 1996).

Desde a sua aprovação, a LDB 9.394/96 vem sofrendo alterações no que se refere à Educação Física Escolar. Logo que foi sancionada, a Educação Física era componente curricular facultativo nos cursos noturnos. Em 2003, foi retirada esta prerrogativa e retornaram no texto da lei as condições que facultavam a prática da Educação Física antes da LDB 9.394/96. Com a medida provisória 746/206 houve a tentativa de retirar a obrigatoriedade da Educação Física do Ensino Médio, porém com a Lei 13415/17 voltaram atrás, devido à mobilização de algumas entidades, como o CBCE- Colégio Brasileiro de Ciências do Esporte e CONFEF- Conselho Federal de Educação Física e a Educação Física permaneceu como componente curricular obrigatório da Educação Básica, nas etapas do Ensino Fundamental e Ensino Médio.

Os PCNs consolidaram a cultura corporal de movimento como objeto de estudo central da disciplina de Educação Física no ensino fundamental, apontando para um avanço na área, buscando uma educação física inclusiva, crítica e preocupada com a formação para a cidadania. $\mathrm{O}$ documento trouxe uma nova perspectiva para este componente curricular, mais próximo a uma concepção crítica da Educação Física, superando os aspectos excludentes e discriminatórios do paradigma anterior, o da aptidão física e do rendimento.

Na segunda versão da BNCC, a Educação Física no Ensino Médio, o documento propõe oferecer o máximo de oportunidades ao estudante para ele estabelecer uma relação qualificada com a cultura corporal de movimento, discutindo temas como o direito às práticas corporais pela comunidade, a relação das práticas corporais com a saúde, o lazer e o tempo livre.

A Educação Física no Ensino Fundamental, na BNCC terceira versão, encaminhada ao CNE, está articulada à Área de Linguagens e é conceituada como componente curricular que tematiza práticas corporais, onde o movimento humano está sempre inserido no âmbito da cultura, sendo estas práticas consideradas fenômenos culturais. 
Nos Anos Iniciais do Ensino Fundamental, a referência central para a configuração dos conhecimentos são as práticas corporais organizadas nas manifestações da cultura corporal de movimento: brincadeiras e jogos, danças, esportes, ginásticas e lutas. Nos Anos Finais do Ensino Fundamental a proposição da BNCC consiste na diversificação das práticas corporais tematizadas, como danças, esportes, ginásticas, lutas e práticas corporais de aventura.

A Reforma do Ensino Médio, que também estabelece algumas alterações para a Educação Física na escola, esta prevê que serão obrigatórios os estudos e práticas da Educação Física, não especificando em quais anos serão realizados, e se estará vinculada à área de aprofundamento escolhida pelo estudante.

Acredita-se que os subsídios teóricos apresentados na BNCC- Educação Física, e nas várias abordagens recentes da Educação Física escolar são suficientes para legitimar a presença da Educação Física no currículo escolar, porém sabe-se que esta discussão é mais complexa. Estudos sobre o cotidiano escolar indicam a necessidade de repensar o papel da Educação Física na escola. Barni e Schneider (2017) apontaram nas suas pesquisas que alguns alunos optam por não frequentar as aulas de Educação Física devido ao fato de estarem descontentes com os conteúdos ou com a forma de atuação dos professores, pois denunciam que as aulas são voltadas para os mais aptos, onde o resultado é supervalorizado e o aluno não produz grandes alterações cognitivas nesta área do conhecimento. As atividades são realizadas de modo fragmentado e sem um objetivo claro. Para estes estudantes a Educação Física se tornou um componente curricular que não trouxe muita contribuição para o seu crescimento pessoal.

Apesar de a legislação educacional apontar a educação física como componente curricular de grande importância para a formação dos alunos, as políticas educacionais implementadas não contribuem para a qualidade do trabalho nesta área do conhecimento. A falta de valorização e formação profissional, o sucateamento das escolas, a falta de organização e planejamento, a sobrecarga de trabalho do profissional, entre outros, são fatores que influenciam as práticas pedagógicas dos professores. Sendo assim, pode-se afirmar que o próprio poder público não cumpre o que está previsto na legislação.

\section{ANÁLISE E DISCUSSÃO}

No decorrer do período histórico analisado, em alguns momentos, houve tentativas de superação dos graves problemas da educação brasileira. Foram criadas novas escolas federais e universidades públicas, houve a ampliação das creches, porém, transformações mais profundas ainda se fazem necessárias para atender a demanda e garantir a qualidade da educação no país. 
$\mathrm{Na}$ conjuntura atual, o governo vem construindo um projeto de educação que desmonta os alicerces do ensino público e gratuito, através do congelamento dos gastos públicos, acarretando a precarização do trabalho na educação com o sucateamento das escolas, arrocho salarial dos professores, entre outras medidas.

A partir da legislação educacional vigente constatamos algumas contradições, a primeira delas é a falta de democracia na elaboração das políticas públicas. O ENE (2014) denunciou a negação dos atores sociais que participaram das CONAES, pois o documento final destes encontros não foi considerado para a elaboração do PNE 2014-2024. Outra incoerência aparente diz respeito ao financiamento da educação. A PEC 55/2016, que congela os gastos públicos, consequentemente promove o corte de investimento na educação num cenário em que as escolas ainda não acolhem todos os alunos na faixa etária recomendada para os diferentes níveis de ensino, dificulta gravemente a expansão, o acesso e permanência na escola, o oferecimento da educação em turno integral apontados como metas pelo PNE. De acordo com o Plano, houve o entendimento de que as verbas públicas destinadas à política educacional não serão utilizadas exclusivamente para a educação pública, mas podem ser direcionadas para a esfera privada, evidenciando a mercantilização da educação.

Em relação à Educação Física escolar, uma das contradições presentes na legislação se refere ao texto da LDB 9.394/96 que permite que a Educação Física seja facultativa a um grupo de alunos, que podem ser dispensados perante a lei. Neste sentido, considerando as propostas teóricas que entendem a Educação Física como área do conhecimento que auxilia o aluno a ter uma compreensão mais completa da realidade, esta determinação legal que estabelece que os alunos com mais de trinta anos, ou que trabalhem, ou que tenham filhos, ou que estejam cumprindo serviço militar inicial sejam dispensados das aulas, reflete um retrocesso no trato com este componente curricular, pois supõe uma visão estritamente biologicista da Educação Física, negando seus aspectos sociológicos e históricos.

A partir da LDB 9.394/96, foram elaborados outros documentos visando orientar a prática pedagógica dos professores de Educação Física, como o Referencial Curricular Nacional para a Educação Infantil e os Parâmetros Curriculares Nacionais para o Ensino Fundamental e Médio. A visão de Educação Física expressa nestes documentos supera a visão anterior pautada na aptidão física e evidencia uma série de conteúdos que devem ser trabalhados nos diferentes níveis de ensino, apontando para a transformação, exigindo dos professores uma prática pedagógica que instigue comportamentos, reflexões e ações que possam repercutir no campo social. 
Na área da Educação Física, tanto nos PCNs, quanto na BNCC os referenciais curriculares elegeram o conceito de cultura corporal de movimento como ponto de convergência da organização dos conteúdos das aulas de Educação Física.

Apesar do conceito de Educação Física ter se modificado nos documentos legais, apontando encaminhamentos metodológicos diferenciados no trato do conhecimento da Educação Física escolar, alguns estudos empíricos como o de Bartholo et.al (2011) apontam que não se obteve os resultados esperados na implementação destas propostas. O referencial teórico apresentado nos documentos não subsidiou a prática pedagógica dos professores no cotidiano escolar, pois as aulas de Educação Física, na sua maioria, ainda têm como conteúdo principal o esporte voltado à aptidão física e ao rendimento e à recreação, onde as atividades físicas são realizadas de modo lúdico.

Para que os professores consigam transformar, aproximar ou questionar a sua prática em relação aos referenciais que os documentos apontam é indispensável uma reflexão sobre o cotidiano de trabalho e os objetivos propostos para a área naquela etapa da educação básica. Para este objetivo ser consolidado é necessária uma formação continuada dos professores, que pode ser realizada no próprio espaço escolar, contemplando a reflexão do Projeto Político Pedagógico da Escola, a troca de experiências e a própria discussão dos referenciais teóricos, na tentativa de avançar na organização e construção coletiva no cumprimento do papel da Educação Física na Escola.

A Reforma do Ensino Médio, proposta pelo governo, com um grande apelo ao senso comum, defende a liberdade de escolha do estudante e a mão de obra qualificada. Alguns estudiosos do Grupo de Trabalho de Política Educacional - GTPE/ANDES (2017) entendem que esta ação apresenta um caráter excludente, constituindo um conjunto de medidas regressivas e violadoras da perspectiva unitária e de formação humana, pois o objetivo deste nível de ensino deveria contemplar a formação geral, a formação para o trabalho e a formação corporal.

Outras críticas se referem à desqualificação dos cursos de licenciatura, visto que será permitido o notório saber como requisito para ministrar aulas no Ensino Médio, desconsiderando o trabalhador com formação específica para atuar na docência.

Em relação à Educação Física, a BNCC prevê a inclusão de estudos e práticas da disciplina, não especificando um tempo pedagógico organizado para as aulas. Deste modo, induz-se ao trabalho da Educação Física como atividade, evidenciando-se um retrocesso na área, onde a Educação Física pode ser desenvolvida dentro de outros conteúdos, sem a garantia de que seja ministrada por um profissional habilitado. Ora, se a BNCC prevê no seu bojo a formação plena do aluno, deveria contemplar todas as dimensões da formação humana. Neste sentido, o componente curricular Educação Física deve permanecer como obrigatória, pois esta trabalha com 
conhecimentos diferenciados e habilidades desenvolvidas nas vivências das práticas corporais que são insubstituíveis para a formação do estudante, tendo um conteúdo que somente ela pode desenvolver no interior da escola, além do domínio cognitivo.

Em relação ao argumento da equidade e igualdade defendido pela implementação da BNCC, salientamos que a Escola pode ser o espaço mais democrático, apesar de, muitas vezes, precário, para o acesso dos jovens às diversas vivências da cultura corporal, ou seja, a não obrigatoriedade da Educação Física deixaria uma grande lacuna na formação dos jovens. Apesar das fragilidades do componente Educação Física no currículo do Ensino Médio, há que se perguntar de que modo podese assegurar aos jovens seu direito ao conhecimento e à cultura se o seu acesso aos bens culturais não será garantido?

Além destes aspetos legais que afirmam que a Educação Física passa a ser prática ou conteúdo na área de linguagens, existem as limitações do espaço físico, material didático, que vem sendo cada vez mais acentuadas pelo corte de investimentos na área da educação, refletindo mais uma contradição que se expressa na impossibilidade concreta de colocar em prática o que está prescrito na legislação.

\section{CONSIDERAÇÕES FINAIS}

O caminho percorrido para este estudo considerou a relação estabelecida entre Educação Física, currículo e legalidade no processo de construção de um projeto de educação. Discutir essas três categorias se dá no sentido de demonstrar que, pensar em um projeto de educação, vai além de interpretar a lei e esperar a sua regulamentação.

Constatamos com este estudo que o projeto de educação presente na legislação remete-nos a um projeto neoliberal que submete a educação pública ao sucateamento e precarização, através do congelamento dos gastos, apontando para a privatização da educação e buscando adaptar o futuro trabalhador num mundo mercadológico, globalizado e competitivo. A legislação vem fragilizando a permanência da Educação Física escolar no currículo da educação básica, com a reforma do ensino médio e a elaboração da BNCC. Estas ações em conjunto, fruto de políticas educacionais antidemocráticas, que não consideram o acúmulo das discussões elaboradas na base dos trabalhadores em educação, não asseguram o que prescreve a LDB 9.394/96 em termos de garantia ao direito a uma educação universal, gratuita, laica e de qualidade e tampouco respondem aos anseios dos cidadãos que querem viver numa sociedade participativa, democrática e igualitária.

A luta pelos direitos é uma construção histórica e a luta pelo direito à educação não é diferente. O compromisso social leva os educadores a lutar por um projeto de educação que priorize 
e fortaleça a cidadania plena dos sujeitos. A história nos mostra que a conquista dos direitos é alcançada por aqueles que necessitam das políticas públicas, que defendem uma sociedade mais justa e igualitária, e a educação é uma das principais pautas da luta social.

Neste sentido, apesar da complexidade e contradições que a construção de um projeto de educação apresenta, consideramos indispensável o protagonismo dos sujeitos envolvidos neste terreno de disputas, para transformar a realidade vigente.

Enfim, neste momento histórico, a luta e a disputa por um projeto de educação que se contrapõe ao vigente deve pautar a democracia em todas as instâncias das gestões educacionais, principalmente no interior das escolas. A busca pela melhoria dos índices de acesso, de permanência e de aprendizagem só será coerente quando de fato acontecer um investimento maior nas políticas públicas de educação, com a valorização dos professores. A luta pela educação se dá junto com outros movimentos que buscam a transformação da sociedade brasileira, por isso a importância da estratégia coletiva na busca da seguridade dos direitos sociais.

Conclui-se este estudo com esta avaliação que busca contribuir para a reflexão que deve ser feita para que a Educação Física seja um espaço cada vez mais comprometido com a propagação dos valores que concretizem um projeto de sociedade buscado e esperado, mais justo, participativo, democrático, humano e fraterno.

\title{
REFERÊNCIAS
}

\author{
ANDES-SN. A Contrarreforma do Ensino Médio: O caráter excludente, pragmático e \\ imediatista da Lei $\mathbf{N}^{\circ} \mathbf{1 3 . 4 1 5 / 2 0 1 7}$. Brasília. 2017.
}

BARNI, Mara Juttel; SCHNEIDER, Ernani José. A Educação Física no ensino médio: Relevante ou irrelevante? Disponível em: https://portal.uniasselvi.com.br. Acesso em: 16 abr 2017.

BARTHOLO, Tiago Lisboa; SOARES, Antônio Jorge Gonçalves; SALGADO, Simone Silva. Educação Física: dilemas da disciplina no espaço escolar. Currículo sem Fronteiras. v.11, n.2, p.204-220, jul/dez 2011.

BRASIL. Lei No 9.394 de 20 de dezembro de 1996. Lei de Diretrizes e Bases da Educação Brasileira.

BRASIL. MINISTÉRIO DA EDUCAÇÃO E DO DESPORTO/ SECRETARIA DE EDUCAÇÃO FUNDAMENTAL. Parâmetros Curriculares Nacionais - Educação Física, Brasília, 1998. BRASIL. Conselho Nacional de Educação. Câmara de Educação Básica. Parecer CNE/CEB 07/2010, de 07 de abril de 2010. Diretrizes Curriculares Nacionais para a Educação Básica. Brasília, 2004. 
BRASIL. Base Nacional Comum Curricular. Proposta Preliminar - Segunda Versão. Ministério da Educação/Conselho Nacional de Secretários de Educação/União Nacional dos Dirigentes Municipais de Educação. Abr. 2016.

BRASIL. Lei No 13.005 de 25 de junho de 2014. Aprova o Plano Nacional de Educação - PNE e dá outras providências.

COLETIVO DE AUTORES. Metodologia de Ensino da Educação Física. São Paulo: Cortez, 1992.

Comitê Nacional em Defesa dos 10\% do PIB para a Educação Pública Já. (ANDES-SN, ANEL, CSP- Conlutas, Oposição de Esquerda da UNE, FENET, ExNEEF, SINASEFE, CFESS). Em Defesa da Educação Pública Gratuita e dos 10\% do PIB para a Educação Pública Já! Encontro Nacional de Educação. Rio de Janeiro. Ago. 2014.

COSTA, Beatriz Aparecida e BORGHI, Raquel Fontes. O Atendimento da Educação Infantil Via Conveniamento: Um Estudo das Justificativas Municipais. Atos de Pesquisa em Educação-PPGEME. PPGE/ME ISSN 1809-0354 v. 8, n. 3, p.1019-1032, set./dez. 2013. DOI http://dx.doi.org/10.7867/1809-0354.2013v8n3p1019-1032.

GOMIDE, Denise Camargo. O materialismo histórico dialético como enfoque metodológico para a pesquisa sobre políticas educacionais. Disponível em:

http://www.histedbr.fe.unicamp.br/acer histedbr/jornada/jornada11/artigos/2/artigo simposio 245 dcgomide@gmail.com.pdf Acesso em 13 mai. 2017.

GONZÁLEZ, Fernando Jaime e FRAGA, Alex Branco. Afazeres da Educação Física na escola: planejar, ensinar, partilhar. Erechim : Edelbra, 2012.

LIBÂNEO, José Carlos. Concepções e práticas de organização e gestão da escola: considerações introdutórias para um exame crítico da discussão atual no Brasil. Artigo publicado na Revista Española de Educación Comparada, Madrid, Espanha. 2007, n 13. Edición monográfica: Administración y gestión de los centros escolares: panorámica internacional.

LIMA, Kátia. Plano Nacional de Educação 2014-2024. Nova fase do privatismo e da certificação em larga escala. Educação Pública - confrontos e perspectivas. Universidade e Sociedade.

ANDES-SN. fev. 2015.

PEREIRA, Talita Vidal e OLIVEIRA, Veronica Borges. BASE NACIONAL COMUM: A autonom ia docente e o currículo único em debate. Revista Teias. v. 15. n. 39. p. 24 42, 2015.

SAVIANI, Dermeval. Pedagogia Histórico-Crítica: Primeiras Aproximações. 8 ed. Campinas/Autores Associados. Campinas. 2003.

SAVIANI, Dermeval. Política educacional brasileira: limites e perspectivas. Revista de Educação PUC Campinas. Campinas, n.24, fev, 2008, p.7-16.

SOBRAL, Osvaldo José. Ensaio sobre o método de pesquisa marxista: uma perspectiva do materialismo dialético. Revista Científica FacMais. v. II. n.1. Ano 2012/2 sem. ISSN 2238-8427. 


\section{NOTAS DE AUTOR}

\section{AGRADECIMENTOS}

Não se aplica.

\section{CONTRIBUIÇÃO DE AUTORIA}

Não se aplica.

\section{FINANCIAMENTO}

Não se aplica.

\section{CONSENTIMENTO DE USO DE IMAGEM}

Não se aplica.

\section{APROVAÇÃO DE COMITÊ DE ÉTICA EM PESQUISA}

Não se aplica.

\section{CONFLITO DE INTERESSES}

Não se aplica.

\section{LICENÇA DE USO}

Os autores cedem à Motrivivência - ISSN 2175-8042 os direitos exclusivos de primeira publicação, com o trabalho simultaneamente licenciado sob a Licença Creative Commons Attribution Non-Comercial ShareAlike (CC BY-NC SA) 4.0 International. Esta licença permite que terceiros remixem, adaptem e criem a partir do trabalho publicado, desde que para fins não comerciais, atribuindo o devido crédito de autoria e publicação inicial neste periódico desde que adotem a mesma licença, compartilhar igual. Os autores têm autorização para assumir contratos adicionais separadamente, para distribuição não exclusiva da versão do trabalho publicada neste periódico (ex.: publicar em repositório institucional, em site pessoal, publicar uma tradução, ou como capítulo de livro), com reconhecimento de autoria e publicação inicial neste periódico, desde que para fins não comerciais e compartilhar com a mesma licença.

\section{PUBLISHER}

Universidade Federal de Santa Catarina. Programa de Pós-Graduação em Educação Física. LaboMídia - Laboratório e Observatório da Mídia Esportiva. Publicado no Portal de Periódicos UFSC. As ideias expressadas neste artigo são de responsabilidade de seus autores, não representando, necessariamente, a opinião dos editores ou da universidade.

\section{EDITORES}

Mauricio Roberto da Silva, Giovani De Lorenzi Pires, Rogério Santos Pereira

\section{HISTÓRICO}

Recebido em: 25 de março de 2019.

Aprovado em: 18 de julho de 2019. 